\title{
Measures of domain-specific resource allocations in life history strategy: Indicators of a latent common factor or ordered developmental sequence?
}

\author{
Rafael Antonio Garcia \\ University of Arizona \\ Candace Jasmine Black \\ University of Arizona \\ Vanessa Smith-Castro \\ Universidad de Costa Rica
}

\author{
Tomás Cabeza de Baca \\ University of California, San Francisco \\ Marcela Sotomayor-Peterson \\ Universidad de Sonora \\ Aurelio José Figueredo \\ University of Arizona
}

The psychometric trait approach to human life history, based on common factor modeling, has recently come under some criticism for neglecting to inquire into the developmental progression that orients and executes human life history trajectories (Copping, Campbell, \& Muncer, 2014). It was asserted that the psychometric approach wholly focuses on creating a higher-order latent factor of life history by subsuming individual differences with developmental and social experiences, ignoring ontogenetic progression. Implicit in the critique is the assumption that developmental perspectives and latent approaches are mutually exclusive and incompatible with each other. The response to this critique by Figueredo and colleagues (2015) proposed instead that developmental perspectives and latent trait approaches are both compatible and necessary to further research on human life history strategies. The current paper uses three independent cross-sectional samples to examine whether models of human life history are best informed by a developmental perspective, psychometric trait approach, or both.

Keywords: Life History Theory; psychometric methods; developmental pathways; latent traits; Bronfenbrenner bioecological model

In this investigation, we seek to determine whether models of human Life History (LH) are best informed by a developmental perspective, psychometric trait approach, or a combination of both. We briefly describe what LH theory is, then outline each approach to the study of human LH strategy and attempt to integrate them into a more comprehensive model of LH epigenesis. We then present three tests of this integrated epigenetic model, in comparison and contrast to two more restricted models, using a nationally-representative USA adult sample and three convenience samples, one USA and two Latin-American college student samples. 


\section{LH Theory}

LH theory is a mid-level theory derived from general evolutionary theory (MacArthur and Wilson, 1967; Wilson, 1975) that describes the strategic allocation of bioenergetic and material resources into Somatic Effort, resources used toward individual survival, and Reproductive Effort, resources used toward genetic survival via the production (Mating Effort) and support of offspring (Parental Effort). Originally developed to explain the changes in growth, reproduction, and survivorship of different species over evolutionary time in response to density-dependent selection (Pianka, 1970), LH theory has since been used to compare behavioral strategies within species (Rushton, 2004). Individuals or species can thus be characterized as being predominantly Slow LH (allocating Somatic over Reproductive Effort and Parental over Mating Effort; maintenance of self and existing offspring) or Fast LH (allocating Reproductive over Somatic Effort and Mating over Parental Effort; production of new offspring) strategists. These characterizations lead to specific predictions regarding the behavioral decisions that an individual or species will make when presented with relevant environmental conditions. For example, LH theory predicts that a sudden increase in the food supply in areas of low population density (all else being unchanged) will most likely result in Fast LH strategists out-competing their Slower LH counterparts, thus pushing the population-specific LH strategy toward the "Fast" end of the continuum (Ellis, Figueredo, Brumbach, \& Schlomer, 2009).

Investigating $\mathrm{LH}$ strategies in humans has proved to be divisive. While it is apparent in earlier work that LH theory should apply to humans, the manifestations to be expected of differential LH strategies continues to be rather controversial (Copping, Campbell, and Muncer, 2014; Figueredo et al., 2015). The pertinent theories tend to fall into one of two camps: the developmental approach and the trait approach. The developmental approach emphasizes the role of putatively observable evolutionarilyrelevant decision nodes across development to characterize LH strategies, while the trait approach emphasizes overarching behavioral predispositions (e.g., personality and sexual behaviors), that are only indirectly observable, to attempt to do the same. The basic characteristics of each approach will now be discussed in turn.

\section{Developmental LH Model}

Traditional developmental models of human LH (Nettle, Coals, \& Dickins, 2011) have purported that salient behavioral cues from the environment transmute children's socioemotional and physical functioning by altering cognitive "inner-working models" of caregiver attachment and to worldviews of the environment (Ross \& Hill, 2002) and 
producing unpredictability schemas that orient an individual toward expectations of unpredictability (Cabeza de Baca et al., 2016). Later LH models of middle childhood, such as the psychosocial acceleration model, extend these previous developmental paradigms by positing that physiological mechanisms and switch-points associated with adrenarche may organize adult life history trajectories based on prior experiences and behaviors learned inside and outside the household environment (Del Giudice, 2014).

With its roots in ecology and evolutionary biology, LH theory has traditionally relied upon biometrically obtained characteristics of species and individuals to classify Slow and Fast LH strategists (e.g., age at menarche, age at sexual debut, and number of offspring). This tradition in observable biometric indicators has carried over directly into the developmental approach to LH theory, often functioning as the operationalizations of LH strategy.

These operationalizations and confidence in their validities, to the exclusion of other possible indicators, have resulted in some friction between proponents of the developmental approach and the trait approach. The general position taken by critics of the trait approach is that the trait approach that incorporates aggregated psychosocial measures is incongruent with traditional developmental paradigms of LH theory because it omits the influence of the developmental decision nodes that are of interest to developmental researchers (Ellis, 2004; Ellis et al., 2009; Copping, Campbell, \& Muncer, 2014). A primary goal of the developmental approach has been to identify what ecological conditions lead to which decisions at key decision nodes. Further, the developmental approach attempts to describe how these individual differences in LH Strategies (these decision profiles) affect various outcomes, more commonly health outcomes. For example, some of the earlier work in the developmental approach such as the psychosocial acceleration model (Belsky, Steinberg, \& Draper, 1991) posited that household conditions (e.g., conflict, father absence) in early childhood function as salient cues to the developing child. As a result of household conditions psychological traits such as attachment should be linked to physical development in behavior later in life such as pubertal timing and pair-bonding.

\section{Trait LH model}

In parallel to the developmental approach, which emphasizes the unfolding of key developmental decision nodes to determine LH strategy, the trait approach emphasizes the coordination of various strategies into a single higher-order composite LH strategy factor (the "K-Factor"), representing LH speed. While this approach has occasionally used biometric indicators of biologically-defined critical life events (e.g., Cabeza 
de Baca \& Figueredo, 2014), it has predominantly used evolutionarilyrelevant psychosocial indicators to map some of the broader nomological net (Cronbach \& Meehl, 1955), encompassing behavioral and cognitive manifestations, in which LH theory is embedded.

For example, while traditional developmental models, such as the psychosocial acceleration model, predict that psychometric indicators of early childhood attachment style should be modeled as causally prior to biometric indicators of LH strategy, the trait approach predicts that both psychometric indicators of childhood attachment style and biometric indicators of LH strategy are merely different indicators of a more fundamental LH speed (as operationalized by the "K-Factor").

\section{The Integrative Biopsychosocial Model}

While the hypothesized developmental trajectories and their corresponding decision nodes are important components of LH development, they are almost certainly not the only components worth investigation. More sophisticated developmental models, such as Bronfenbrenner's Bioecological Model (Bronfenbrenner \& Morris, 2006), emphasize four key factors: (1) process, (2) individual (3) context, and (4) temporality. These models broadly suggest that ontogeny is a progression across the life-course that involves the transaction between individual characteristics, the context they reside in, and the time space the events are occurring. The transaction between the individual and context is further refined by multilevel systems of context known as the macrosystem, exosystem, mesosystem, and microsystem. Factors within and across these systems interact with each other and with the individual to produce a progression of development that later influences other stages of development. Figure 1 displays a graphical representation of this model.

Integrating the Bioecological Model with LH theory, it becomes evident that within the confines of species-typical developmental constraints and other forms of biological preparedness (Figueredo, Hammond, \& McKiernan, 2006; West-Eberhard, 2003), developmental plasticity may produce coordinated suites of traits that emerge as higher-order constructs when examined from a trait perspective (Figueredo et al., 2006). Thus, the theoretical rationale behind the Integrative Biopsychosocial Model can be described as follows. Understanding that the slow life history "K-Factor" is highly heritable (broad sense $h^{2}=.60-.70$; Figueredo et al., 2004; Figueredo \& Rushton, 2009), we may consider the influence of that common factor on successive developmental stages to be mostly (meaning about a "two-thirds majority") interpretable as the continuing effects of shared genes on the hypothesized developmental sequence. Consistent with the results of longitudinal analyses carried out on the MIDUS Wave 1 and Wave 2 data, Figueredo, Cabeza de Baca, and 
Figure 1. Bronfenbrenner's (1979) Ecological Systems Theory: Hierarchically Nested Concentric "Spheres" of Organism-Environment Interaction

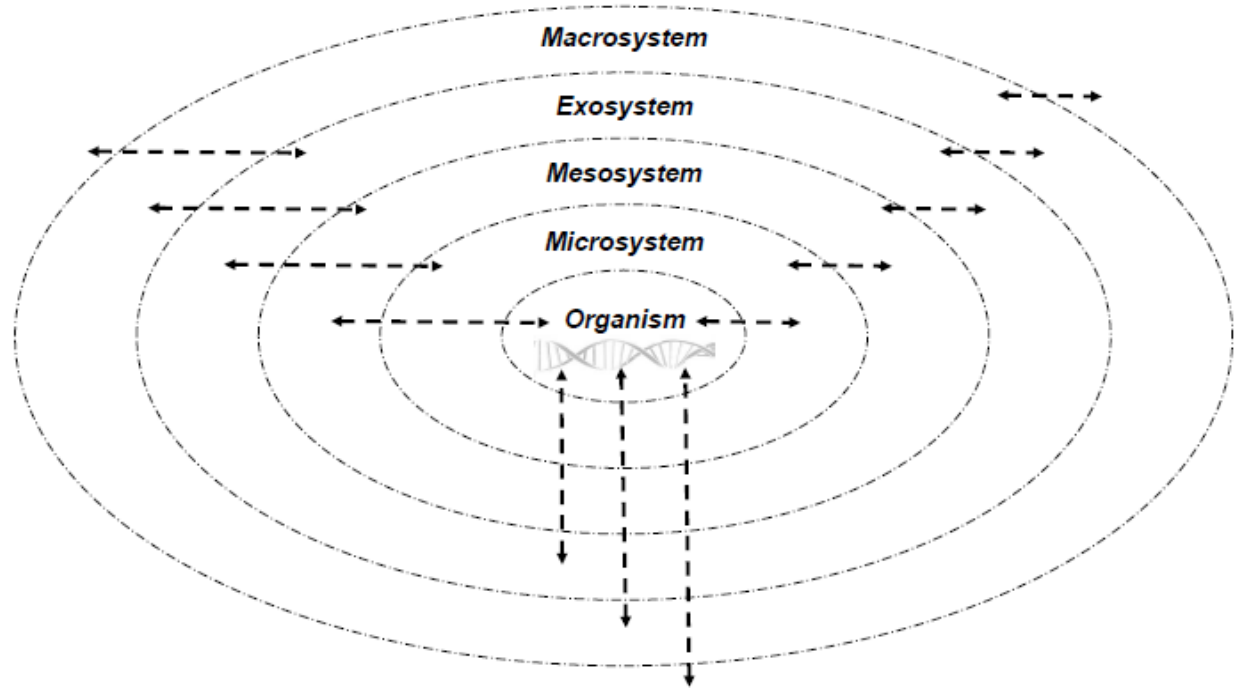

Black (2014), heritable differences explain a substantial portion of the measurable temporal stability in both higher-order and lower-order life history factors over a 10-year interval during adulthood, rivaled only in magnitude by the influence of the non-shared environment. Also consistent with the evolutionary developmental theories of West-Eberhard (2003) and Figueredo, Hammond, and McKiernan (2006), significant genetic interaction ("guidance") is required at every step of the epigenetic process of development, and are naturally selected to do so by the processes of genetic accommodation and genetic assimilation (sensu Waddington, 1957).

The Integrative Biopsychosocial Model formalizes these relations as specifying that the K-Factor should have a direct effect on the emergence of each successive developmental stage in addition to its indirect effects through the sequence of consecutive stages. This means that the hypothesized regulatory genes (see Figueredo et al., 2004, 2007) that coordinate the multiplicity of life history traits into coherent and adaptive patterns (represented psychometrically by the latent common factors) are active and influential throughout biological and behavioral development. For example, once puberty is triggered, the process of sexual maturation entails the coordination of a variety of anatomical, physiological, and psychosocial changes, and this coordination is controlled by the genetically-mediated responses of the various target tissues to pubertal hormones. When a molecule of steroid hormone is captured by a hormone receptor at the cell membrane, the hormone is brought by that receptor to the cell nucleus and into contact with the chromosomes contained therein 
to directly moderate DNA expression, as by upregulating or downregulating gene products.

Thus, the genes do not merely "set the stage" passively for either biological or psychosocial development by initially constructing the basic structures of the organism, such as the body and the brain, upon which the environment presumably thereafter acts: they are consistently active in reconstructing that organism throughout development, in a state of perpetual causal "transaction" with the interior and exterior environments. This explains why, although there are many environmental factors which might influence the timing of pubertal stages, the developmental structuring of anatomical, physiological, and psychosocial changes (meaning the overall pattern of what puberty entails) is not very subject to environmental disruption once the process has been triggered. Evaluating the relative performance of the integrative model represents an empirical test of that theoretical framework.

This evolutionary-developmental interpretation of the Bronfenbrenner model is consistent with previously published interpretations (Figueredo, Brumbach, Jones, Sefcek, Vásquez, \& Jacobs, 2007), but is not to be taken a literal application of the original work.

\section{The Present Set of Studies}

In this investigation, we present systematic comparisons among these three alternative models using a nationally-representative USA adult sample and three convenience samples, one USA and two Latin-American college student samples. The key assertions made by certain critics of the ALHB (Copping et al., 2014) were that the ALHB subscales should not be interpreted as indicators of a latent common factor, but instead should be represented as standing in causal relations to each other. What we did was compare one model that specified a latent common factor to account for the covariances among subscales to another model that specified a series of causal relations among them reflecting a well-accepted developmental theory that we believed to be applicable (Bronfenbrenner, 1973, 1979). We then created an integrative model that incorporated elements of both to see if this improved upon the performance of either or both of the simpler models.

\section{Methods}

The present studies were designed to test which life history model best describes the data, balancing parsimony with explanatory power. In order to test these models, three previously used cross-sectional data sets were used: (1) a U.S. nationally-representative sample; (2) a U.S. college student 
convenience sample; (3) two non-U.S. college student convenience samples from different Latin American countries.

\section{Participants}

Study 1. Data were obtained from the Wave I version of Midlife in the United States study (MIDUS; Brim et al., 2000). For the present study, we utilized the same sample of participants previously described in Figueredo, Cabeza de Baca, \& Black, (2014). The sample consisted of 2257 non-twins (see Figueredo, Cabeza de Baca, \& Black (2014) for further information regarding the sample and the construction of the measures). The sample had a mean age of $46.65(S D=12.83$, range 20-74) and was almost half male/female (Female: 52.41\%; Male: 47.59\%).

Study 2. Data were collected from 437 female undergraduate students from a Southwestern United States University. Data were collected via online internet questionnaires, and participants received academic credit for voluntarily completing this packet of questionnaires. The sample had a mean age of $18.55(S D=0.90$, range $18-23)$.

Study 3. Data were collected from 149 Mexico and 152 Costa Rica undergraduate students. Data were collected via paper and pencil questionnaires. The characteristics of these samples were previous reported on in Sotomayoro-Peterson, Cabeza de Baca, Figueredo, and Smith-Castro (2013). The combined Latin American sample had a mean age of $21.23(S D=4.02$, range $17-57)$ and was predominantly (61.72\%) female, with the remaining proportion (38.21\%) male.

\section{Measures}

Slow Life History (K-Factor). The three samples included measures of slow life history $(K)$, as specified by Figueredo and colleagues (e.g., Figueredo et al., 2005; 2006; 2007). Broadly, the measures across the samples utilize items and subscales that capture the six social affordance areas in which individuals can invest time and energy (Figueredo, Patch, \& Ceballos Gomez, 2015). Prior research (e.g., Figueredo, Woodley, Brown, \& Ross, 2013) has compared across disparate measures of psychometric life history and yielded similar results.

Study 1. The first study utilized subscales in the MIDUS that had been previously identified as converging on a single life history factor (Figueredo et al., 2004, 2007), but were reorganized into the different functional domains reflected in the subscales of the Arizona Life History Battery (ALHB; Figueredo, 2007) as had been done in Figueredo, Woodley, Brown, and Ross (2013), which supported the validity of these secondary aggregations by showing the part-whole correlations between each of the original MIDUS K-Factor indicators and the functional (ALHB- 
inspired) composites to which it had been theoretically assigned. In that study, multiple MIDUS scales had been aggregated into the functional domains specified by the ALHB for comparison, but the component MIDUS scales were in no way modified for this purpose. For the present analysis, we utilized the same measures previously discussed in (Figueredo, Cabeza de Baca, \& Black, 2014).

Studies 2 and 3. The two remaining studies directly utilized the Arizona Life History Battery (ALHB; Figueredo, 2007) which is comprised of 8 subscales: (1) The Mini-K short form (Figueredo et al., 2006); (2) Insight, planning, and control; (3) Mother-father relationship quality; (4) Family social contact and support; (5) Friends social contact and support; (6) Experiences in close relationships; (7) General altruism; and (8) Religiosity. Although the ALHB was not modified in any way for the present study, it was originally designed with an evolutionary interpretation of the Bronfenbrenner model in mind.

\section{Statistical Analyses}

All statistical analyses were performed using SAS 9.4. A two stage analytical strategy was employed in all three studies due to limitations of the sample sizes. The first stage was estimating unit-weighted common factor scores (Gorsuch, 1983) by using SAS PROC STANDARD and DATA. All non-missing subscales from their respective factors were standardized and averaged to create each of the unit-weighted factors(Figueredo, McKnight, McKnight, and Sidani, 2000; McKnight, McKnight, Sidani, and Figueredo 2007). Cronbach's alphas and covariance matrices of the subscales were computed using SAS PROC CORR. In the second stage, all of the estimated unit-weighted factor scores were entered as manifest variables for multivariate causal analysis within a single structural equation model.

In all three studies, Factor-Analytic Structural Equations Modeling (FASEM) was performed by SAS PROC CALIS to provide a multivariate causal analysis of the measurement and structural relations between these constructs. FASEM results were evaluated using a chi-square statistic, the Bentler-Bonnett Comparative Fit Index (CFI), and the Root Mean Squared Error of Approximation (RMSEA). Index values of the CFI greater than 0.90 are considered satisfactory levels of practical goodness-of-fit (Bentler \& Bonnett, 1980; Bentler, 1995), whereas RMSEA values of 0.05 or less are considered indications of good fit. Values between 0.08 and 0.10 are forconsidered indications of a mediocre fit, and values greater than 0.10 are considered indications of a poor fit (Steiger \& Lind, 1980; Browne \& Cudeck, 1993). The CFI was selected because it is adjusted for model parsimony and performs well with moderate to small sample sizes $(N<$ 250), especially with Maximum Likelihood estimation (Bentler, 1990; $\mathrm{Hu}$ 
\& Bentler, 1995). Alternative fit indices, such as the Bentler-Bonett NonNormed Fit Index (NNFI), provide poor estimates of model fit with smaller samples (Hu \& Bentler, 1995).

Additionally, we performed a series of multisample analyses in Study 3, comparing the Costa Rican and Mexican samples. This technique is used to test the adequacy of a FASEM to data from two independent samples (Bentler 1995; Byrne 1994). The same model is tested simultaneously on the data from both samples and cross-sample equality constraints may be tentatively imposed, which force either all or some specified subset of the model parameters for both samples to be equal. The otherwise identical multisample model may be tested with and without either some or all of these equality constraints imposed and then compared for relative goodness of fit to the data. A significant difference between the goodness of fit of the constrained and unconstrained models would indicate either a statistical or practical rejection of the hypothesized equality constraints, indicating that the model parameters are significantly different between the samples.

\section{Results}

\section{Study 1}

Three models were tested: a trait only model, a developmental pathways only model, and an Integrative Biopsychosocial Model. In the trait only model (displayed in Figure 2), a latent common factor was extracted from the alternative resource-allocation domains described by six subscales of the ALHB: (1) Biological Mother and Father, (2) Immediate and Extended Family, (3) Romantic Partner Attachment, (4) Friends and Associates, (5) General Social Altruism, and (6) Regular Religious Practices. The developmental pathways only model (displayed in Figure 3) arranged these same subscales in a Bronfenbrenner-inspired cascade of hierarchically nested systems, ranging from microsystems (parental, familial, and romantic) out to macrosystems (religiosity). Figure 4 displays the theoretically expected correspondence of the ALHB domainspecific resource allocation subscales with the nested Bronfenbrenner systems.

Lastly, the epigenetic model (Figure 5) was an integration of the previous two models, and hence served as our inclusive model. The Integrative Biopsychosocial Model allowed for both the common factor loadings and developmental pathways to be estimated simultaneously, permitting each subscale to be related because of some common mechanism and independently affect the next step in the developmental causal chain. 
Figure 2. The "K-Factor" ALHB Common Factor Only Trait Model

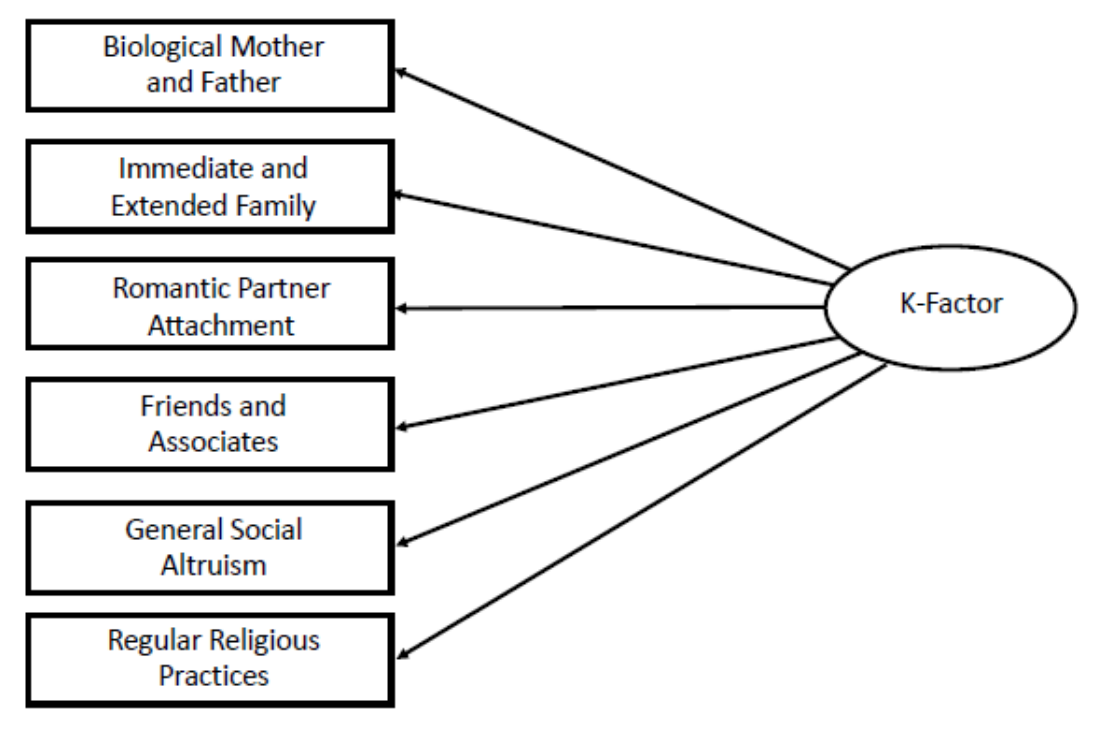

Figure 3. ALHB-Structured "Bronfenbrenner-Inspired" Pathways Only Developmental Model

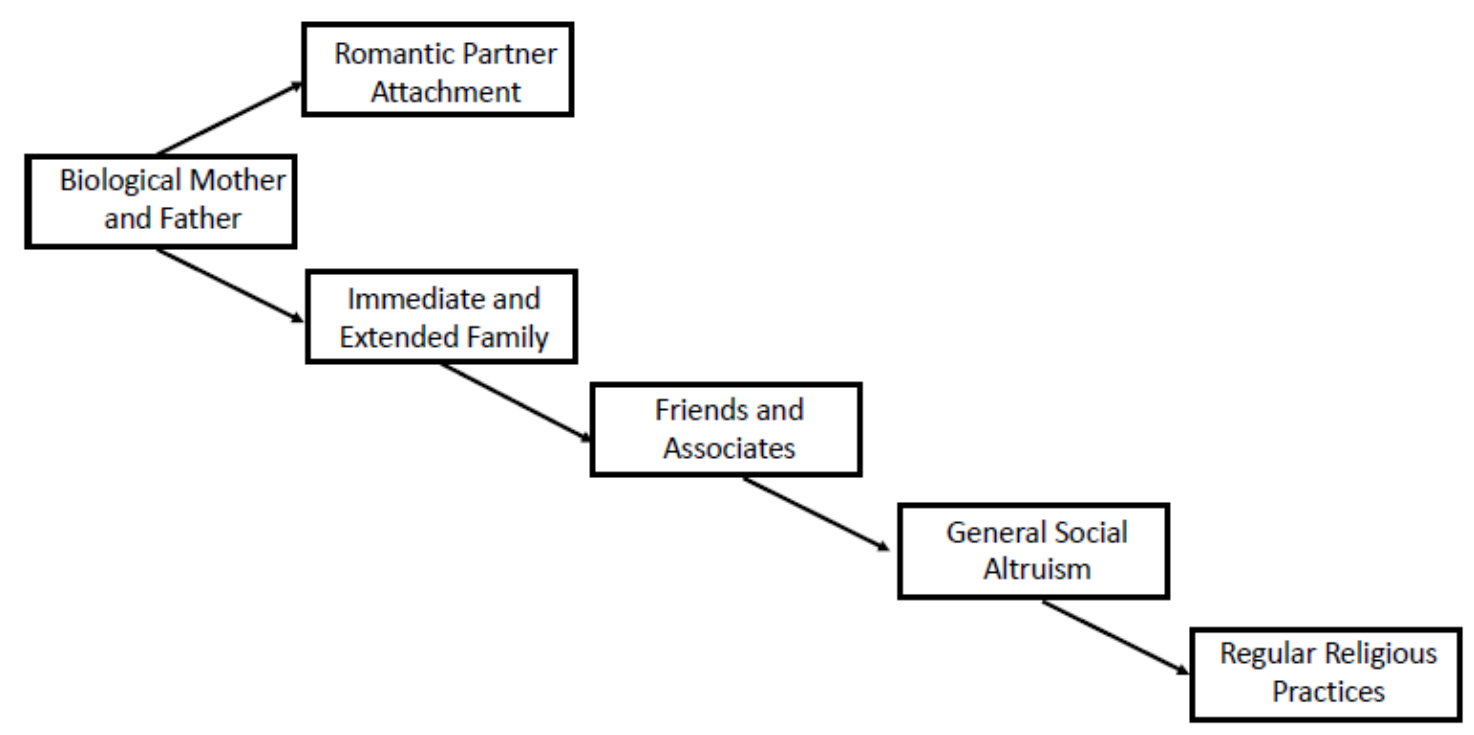


Figure 4. Domain-Specific ALHB Resource Allocations: Predominant Linkages to Social Affordances

\begin{tabular}{|c|c|}
\hline $\begin{array}{l}\text { Biological Mother } \\
\text { and Father }\end{array}$ & $\begin{array}{l}\text { Microsystem Parent- } \\
\text { Offspring Affordances }\end{array}$ \\
\hline $\begin{array}{l}\text { Immediate and } \\
\text { Extended Family }\end{array}$ & $\begin{array}{l}\text { Microsystem Nepotistic } \\
\text { Affordances }\end{array}$ \\
\hline $\begin{array}{c}\text { Romantic Partner } \\
\text { Attachment }\end{array}$ & $\begin{array}{c}\text { Microsystem } \\
\text { Inter-Sexual Affordances }\end{array}$ \\
\hline $\begin{array}{l}\text { Friends and } \\
\text { Associates }\end{array}$ & $\begin{array}{l}\text { Mesosystem Intra- and } \\
\text { Inter-Sexual Affordances }\end{array}$ \\
\hline $\begin{array}{l}\text { General Social } \\
\text { Altruism }\end{array}$ & $\begin{array}{c}\text { Exosystem } \\
\text { Social Affordances }\end{array}$ \\
\hline $\begin{array}{l}\text { Regular Religious } \\
\text { Practices }\end{array}$ & $\begin{array}{c}\text { Macrosystem } \\
\text { Social Affordances }\end{array}$ \\
\hline
\end{tabular}

Figure 5. Integrative Latent Common K-Factor plus "BronfenbrennerInspired” Developmental Pathways Epigenetic Model

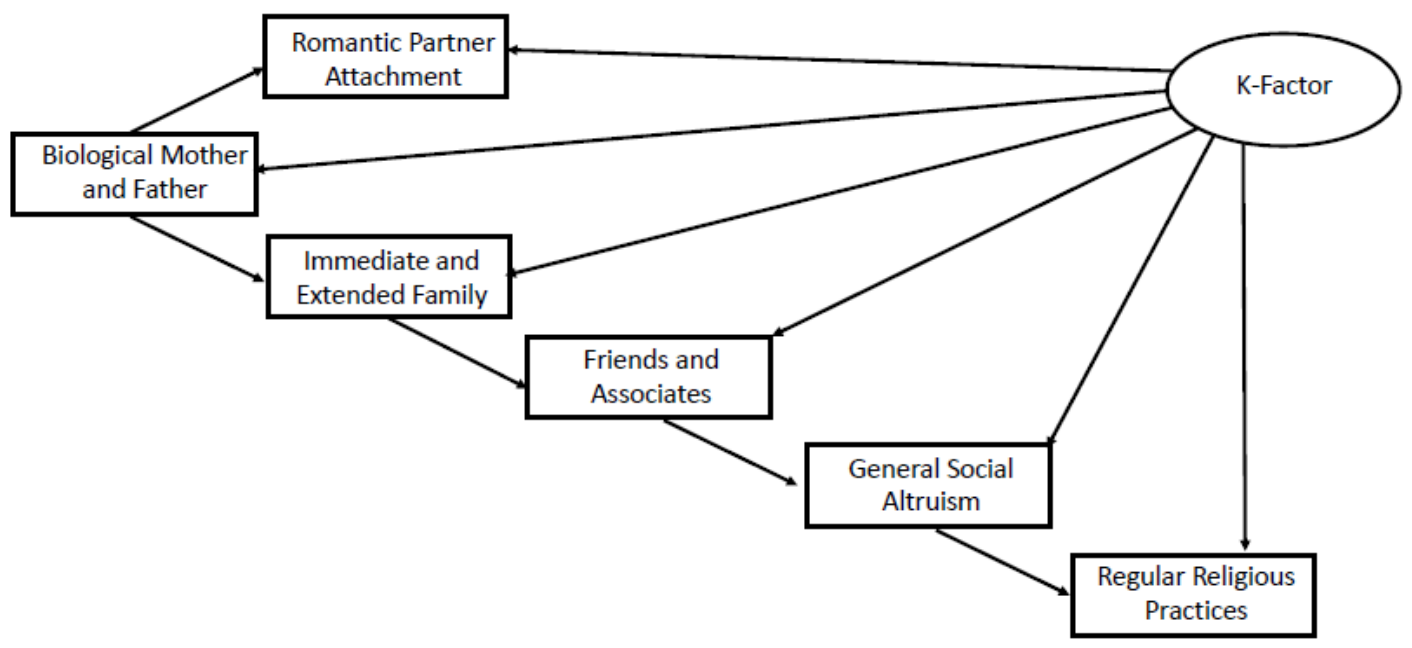

The resulting structural models can be seen in Table 1 (also see Appendix Figures A-C). As hypothesized, the Integrative Biopsychosocial Model fit the data better $\left(\chi^{2}{ }_{4,2257}=66.5, p<.05 ; \mathrm{RMSEA}=.08 ; \mathrm{CFI}=.97\right)$ 


\section{GARCIA ET AL.}

than alternative ("restricted") models based on either (1) the common factor alone $\left(\chi^{2}{ }_{9,2257}=142.9, p<.05\right.$; RMSEA $=.08$; CFI $\left.=.94\right)$ or $(2)$ the developmental sequence alone $\left(\chi^{2}{ }_{10,2257}=849.9, p<.05\right.$; $\mathrm{RMSEA}=.19$; CFI $=.58)$. Using hierarchically nested model comparisons, the integrative model was found to be a superior model by absolute, practical, and parsimonious fit indices (Table 2). Simply put, the Integrative Biopsychosocial Model was the optimal model among the alternatives tested.

Table 1

Alternative SEM/MSM Specification for Samples 1-3

\begin{tabular}{|c|c|c|c|c|c|}
\hline \multicolumn{6}{|c|}{ Sample 1: Nationally-Representative MIDUS Survey Mixed-Sex Sample } \\
\hline Alternative SEM Specifications & $\chi^{2}$ & df & $p(\mathrm{Ho})$ & RMSEA & CFI \\
\hline $\begin{array}{l}\text { SEM 1: Integrative Model } \\
\text { (K-Factor + Bronfenbrenner Pathways) }\end{array}$ & $66.5^{*}$ & 4 & .0000 & .08 & .97 \\
\hline SEM 2: Latent $K$-Factor Alone & $142.9^{*}$ & 9 & .0000 & .08 & .94 \\
\hline SEM 3: Bronfenbrenner Pathways Alone & $849.9^{*}$ & 10 & .0000 & .19 & .58 \\
\hline \multicolumn{6}{|c|}{ Sample 2: USA Female Student Samples } \\
\hline Alternative SEM Specifications & $\chi^{2}$ & df & $p(\mathrm{Ho})$ & RMSEA & CFI \\
\hline $\begin{array}{l}\text { SEM 1: Integrative Model } \\
\text { (Mini-K + Bronfenbrenner Pathways) }\end{array}$ & $23 \cdot 7^{*}$ & 10 & .0085 & .06 & .98 \\
\hline $\begin{array}{l}S E M \text { 2: Mini-K-Proxy for } \\
\text { Latent Common K-Factor Alone }\end{array}$ & $153 \cdot 7^{*}$ & 15 & .0000 & .15 & .75 \\
\hline$S_{\text {SEM 3: Bronfenbrenner Pathways Alone }}$ & $36.5^{*}$ & 10 & .0001 & .08 & .95 \\
\hline \multicolumn{6}{|c|}{ Sample 3: Combined Mexican and Costa Rican Mixed-Sex Student Samples } \\
\hline Alternative MSM Specifications & $\chi^{2}$ & df & $p(\mathrm{Ho})$ & RMSEA & CFI \\
\hline $\begin{array}{l}\text { MSM 1A: Integrative Model } \\
\text { (Mini-K + Bronfenbrenner Pathways) }\end{array}$ & $53 \cdot 5$ & 44 & .1544 & .04 & .97 \\
\hline $\begin{array}{l}\text { MSM 2A: Mini-K-Proxy for } \\
\text { Latent K-Factor Alone }\end{array}$ & $133 \cdot 5^{*}$ & 49 & .0000 & .11 & .77 \\
\hline $\begin{array}{l}\text { MSM 3A: Bronfenbrenner } \\
\text { Developmental Pathways Alone }\end{array}$ & $73.6^{*}$ & 44 & .0034 & .07 & .92 \\
\hline
\end{tabular}


RESOURCE ALLOCATION IN LIFE HISTORY STRATEGY

Table 2

Nested Model Comparisons of Alternative Specifications for Samples 1-3

Sample 1: Nationally-Representative MIDUS Survey Mixed-Sex Sample

\begin{tabular}{lccccc}
\hline \multicolumn{1}{c}{ Nested Model Comparisons } & $\Delta \chi 2$ & $\Delta \mathrm{df}$ & $p(\mathrm{Ho})$ & $\Delta \mathrm{RMSEA}$ & $\Delta \mathrm{CFI}$ \\
\hline $\begin{array}{l}S E M \\
\text { Comparison "Difference" Tests }\end{array}$ & $76.4^{*}$ & 5 & .0000 & .00 & -.03 \\
& & & & & \\
$\begin{array}{l}S E M \\
\text { Comparison " }- \text { "Difference" Tests }\end{array}$ & $783.4^{*}$ & 6 & .0000 & .11 & -.39 \\
\hline
\end{tabular}

Sample 2: USA Female Student Samples

\begin{tabular}{lccccc}
\hline \multicolumn{1}{c}{ Nested Model Comparisons } & $\Delta \chi^{2}$ & $\Delta \mathrm{df}$ & $p(\mathrm{Ho})$ & $\Delta$ RMSEA & $\Delta$ CFI \\
\hline $\begin{array}{l}S E M \\
\text { Comparison "Difference" Tests }\end{array}$ & $130.0^{*}$ & 5 & .0000 & .09 & -.23 \\
& & & & & \\
$\begin{array}{l}S E M \\
\text { Comparison "Difference" Tests }\end{array}$ & $12.8^{*}$ & 0 & Undefined & .02 & -.03 \\
\hline
\end{tabular}

Sample 3: Combined Mexican and Costa Rican Mixed-Sex Student Samples

\begin{tabular}{lccccc}
\hline \multicolumn{1}{c}{ Nested Model Comparisons } & $\Delta \chi 2$ & $\Delta \mathrm{df}$ & $p(\mathrm{Ho})$ & $\Delta \mathrm{RMSEA}$ & $\Delta \mathrm{CFI}$ \\
\hline $\begin{array}{l}M S M \text { 2A - MSM 1A: Nested Model } \\
\begin{array}{l}\text { Comparison "Difference" Tests } \\
\text { MSM 3A - MSM 1A: Nested Model }\end{array}\end{array}$ & $80.0^{*}$ & 5 & .0000 & .08 & -.20 \\
$\begin{array}{l}\text { Comparison "Difference" Tests } \\
\text { M }\end{array}$ & $20.1^{*}$ & 0 & Undefined & .03 & -.05 \\
\hline
\end{tabular}

\section{Study 2}

Because of the relatively small sample sizes in Studies 2 and $3(N=437$ and $N=296$, respectively), the Integrative Biopsychosocial Model specified in Study 1 resulted in model parameters out-of-bounds or nonestimable when run on the smaller samples (the trait only and developmental pathways only models were estimable and are shown in Appendix Figures D-E). To overcome this statistical limitation, we used the Mini-K subscale of the ALHB as a proxy for the general latent K- 
Factor. This decision was appropriate as the meta-analytic estimate of the disattenuated population-level validity of the Mini-K with respect to the KFactor is $\rho=.91$ (Figueredo, Wolf, et al., 2014). To make the models most internally comparable (Figures 6-8), the developmental model was modified to better reflect what we believe is the chief claim of developmental evolutionary psychologists: the hypothetical construct identified using the trait approach is in reality not a latent, but an emergent construct (Figure 7). That is to say, it is a "side-effect" of causal chain, not a cause itself.

Figure 6. Mini-K as Proxy "Latent Construct” Trait Model

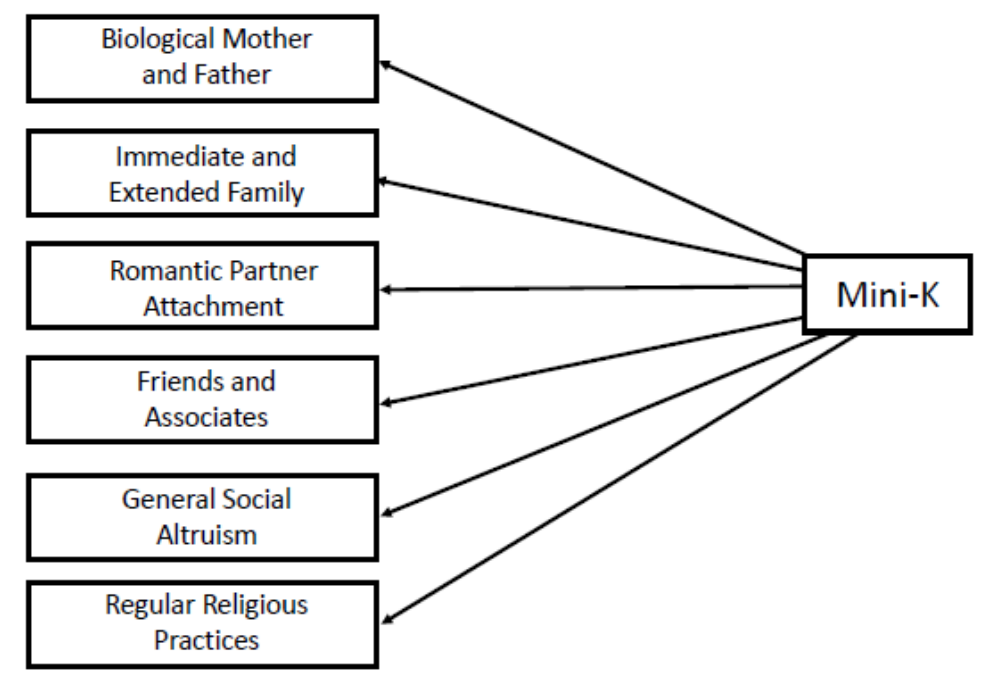

Figure 7. Integrative Mini-K as "Emergent Construct" plus "Bronfenbrenner-Inspired" Developmental Pathways Epigenetic Model

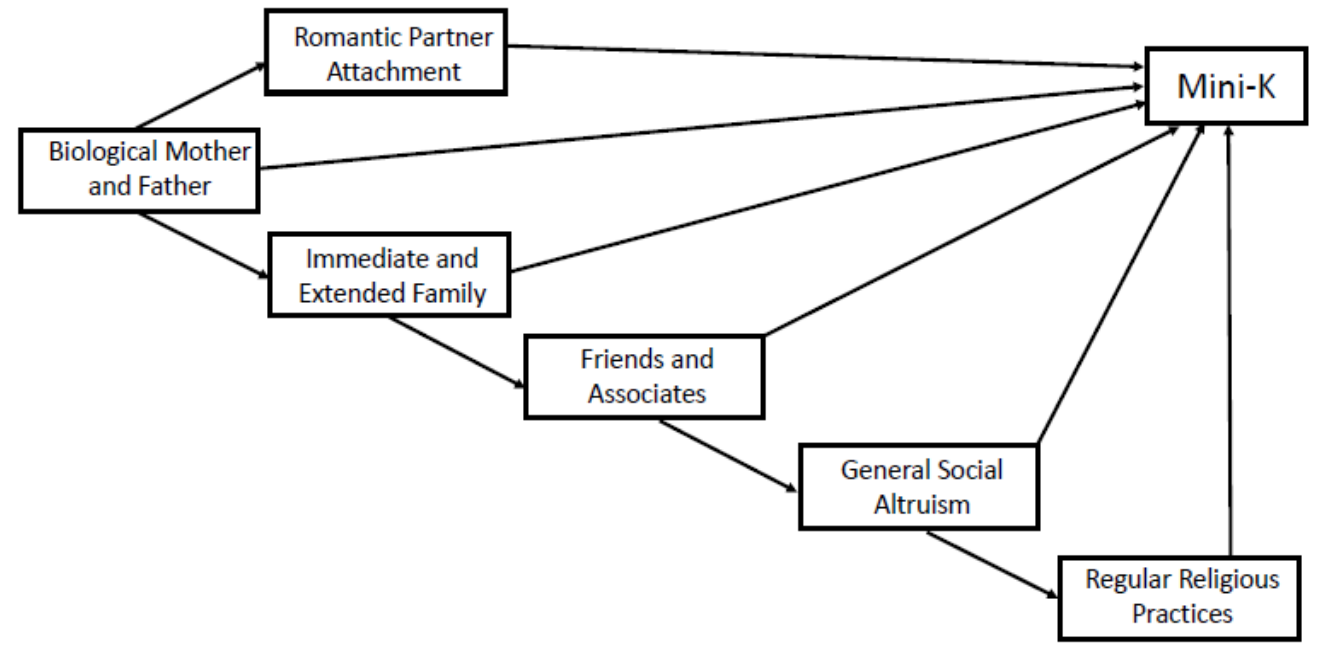


Figure 8. Integrative Mini-K as Proxy "Latent Common K-Factor" plus "Bronfenbrenner-Inspired" Developmental Pathways Epigenetic Model

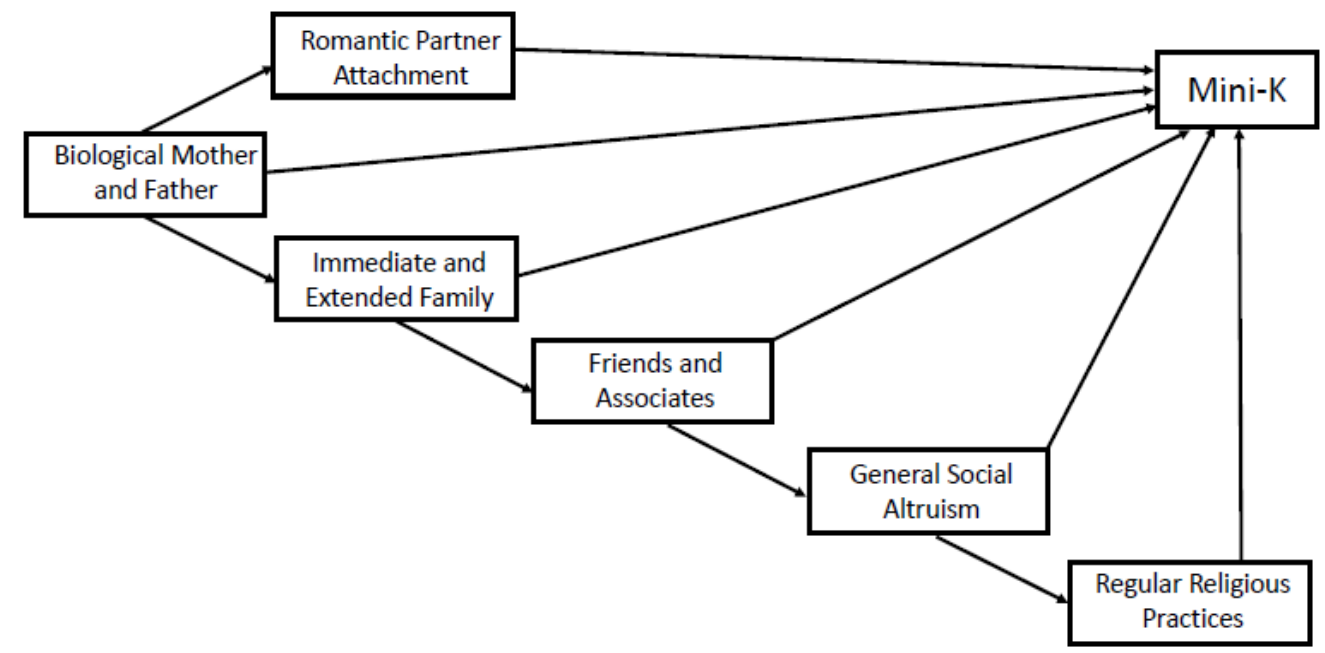

The resulting structural models can be seen in Table 1 (see also Appendix Figures F-H). As hypothesized, the Integrative Biopsychosocial Model fit the data substantially better $\left(\chi^{2} 10,437=23.67, p<.05\right.$; RMSEA $=$ .06 ; CFI $=.98$ ) than alternative ("restricted") models based on either (1) the common factor alone $\left(\chi^{2} 9,437=52.05, p<.05\right.$; RMSEA $=.11$; CFI $\left.=.86\right)$ or (2) the developmental sequence alone $\left(\chi^{2}{ }_{10,437}=36.51, p<.05\right.$; RMSEA $=.08 ; \mathrm{CFI}=.91)$. Using hierarchically nested model comparisons, the Integrative Biopsychosocial Model was found to be a superior model by absolute, practical, and parsimonious fit indices (Table 2), just as in Study 1. Once again, the Integrative Biopsychosocial Model was the optimal model among the alternatives tested.

\section{Study 3}

Before proceeding with the structural models estimated in Study 2, two multisample structural equations models were compared. The first was a fully-constrained model, in which all parameters between the samples were fixed to be equal except for the observed variance in the proxy variable $\left(\chi^{2} 44,296=53.5, p=.15 ; \mathrm{RMSEA}=.04 ; \mathrm{CFI}=.97\right)$. The second model was a fully-unconstrained model, in which all of the parameters between the samples were allowed to be freely estimated $\left(\chi^{2}{ }_{21,296}=33.2\right.$, $p=.04$; RMSEA = .06; CFI = .97). A nested model comparison showed that the two models did not differ significantly $\left(\Delta \chi^{2}{ }_{23}, 296=20.3, p=.62\right.$; $\Delta \mathrm{RMSEA}=-.02 ; \Delta \mathrm{CFI}=.00)$. In other words, any differences between the two samples were trivial and not detectable using our statistical tests. 
Because of this, we did not further explore possible structural differences between the samples for each alternative life history model.

The resulting structural models can be seen in Table 1 (see also Appendix Figures I-M). As hypothesized, the Integrative Biopsychosocial Model fit the data better $\left(\chi^{2}{ }_{44,296}=53.5, p=.15 ;\right.$ RMSEA $\left.=.04 ; \mathrm{CFI}=.97\right)$ than alternative ("restricted") models based on either (1) the common factor alone $\left(\chi^{2} 49,296=133.5, p<.05\right.$; RMSEA $=.11$; CFI $\left.=.77\right)$ or $(2)$ the developmental sequence alone $\left(\chi^{2} 44,296=73.6, p<.05 ; \mathrm{RMSEA}=.07\right.$; $\mathrm{CFI}=$ .92). As in the two previous studies, the Integrative Biopsychosocial Model was found to be a superior model by absolute, practical, and parsimonious fit indices (Table 2), using hierarchically nested model comparisons. As in both Study 1 and Study 2, the Integrative Biopsychosocial Model was the optimal model among the alternatives tested.

\section{Discussion}

The present set of studies were designed to apply the methods of strong inference (Lakatos, 1978) to the problem of comparing and contrasting the relative fit of three alternative models of life history development. Hierarchically nested model comparisons of factor analytic structural equations models were used to evaluate the relative fit of these models (Marsh \& Bailey, 1991; Widaman, 1985).

The first model was a model partially based on Bronfenbrenner's developmental theories of ecological psychology, in which the developing individual encounters successively expanding concentric circles of social interaction with the surrounding environment. These circles were operationalized in these studies by six subscales of the ALHB, each designed to represent a different domain of psychosocial resource allocation, and these subscales were arrayed in the developmental sequence most consistent with the Bronfenbrenner Bioecological Model. These six subscales did not include the Mini-K, which is designed to be domain-general, but some variants of the model used the Mini-K as a proxy for the common factor, in cases where estimation problems were encountered due to reduced sample sizes.

This model is admittedly an extreme form of the developmental pathways model, which nobody in particular has endorsed, in which the influences of no heritable individual differences are explicitly included, and the outcomes of psychosocial interactions at each stage of development uniquely determine the outcomes of interactions at the next stage. These influences could be characterized as falling mostly within the conventional behavioral-genetic category of non-shared environment (although some shared environment is possible but unlikely), in that idiosyncratic interactions at each stage may influence those at the next in 
randomly dissimilar ways for different individuals. One may paraphrase this model in a single popular expression: "one thing leads to another".

The second model was a common factor model, in which the covariances among these same domain-specific subscales were modeled as spuriously rather than directly related to each other, with the common causal influence represented by the K-Factor (sometimes using the Mini-K as a proxy for the latent variable, as explained above, which is the function for which it was explicitly designed). This model represents the behavior exhibited by the individual when encountering these expanding circles of social interaction (operationalized by the six ALHB subscales) as manifestations of an underlying permanent, stable, and highly heritable trait, the fundamental speed of one's life history strategy (operationalized by either the K-Factor or the Mini-K), and not as standing in any direct causal relations to each other throughout development.

This model is admittedly an extreme form of the trait model, which nobody in particular has endorsed, in which the outcomes of psychosocial interactions at each stage of development have no influence upon the outcomes of interactions at the next stage, and the influences of the permanent and stable individual difference trait are the only ones explicitly included. As the particular individual difference trait involved has been shown to be highly heritable (Figueredo et al., 2004; Figueredo \& Rushton, 2009), these influences could be characterized as falling mostly within the conventional behavioral-genetic category of shared genetic influences (although some influence of non-shared environment was also estimated in the models cited), in that the latent trait is hypothesized to influence the outcomes at each successive stage in systematically dissimilar ways for different individuals, depending on one's level of the trait. One may paraphrase this model in the following variant of an equally popular expression: "same thing, different day".

The third model was an integrative model, in which elements of both the first and second model were combined. The six domain-specific ALHB subscales were again arrayed in a Bronfenbrenner-inspired developmental sequence, connected by the theoretically specified causal pathways, but the latent life history speed of the individual (the K-Factor or the Mini-K) was also modeled as having direct influences on each stage of the sequence. This integrative model was based on a more nuanced conception of development, in which epigenetic processes are hypothesized to operate at every stage, with the effects of each encounter with the each of Bronfenbrenner's expanding spheres of the social influence from the everbroadening environment interacting with the genetic preparedness inherent in the latent common factor to jointly shape the next sequential phase of psychosocial development.

This third model is an integrated form of the trait and the developmental pathways models, the outlines of which are at least 
implicit in the theorizing of Bronfenbrenner and others (Bronfenbrenner \& Ceci, 1994; Wachs, 2009; Lemery-Chalfant, Kao, Swann, \& Goldsmith, 2013) and were explicitly endorsed by Figueredo and colleagues (2015), in which the influences of both the permanent and stable individual difference trait and the outcomes of psychosocial interactions at each stage of development upon the outcomes of interactions at the next stage are also explicitly included. Once again, as the particular individual difference trait involved has been shown to be highly heritable (Figueredo et al., 2004; Figueredo \& Rushton, 2009), these influences could be characterized as falling mostly within the conventional behavioral-genetic category of gene-environment interactions (encompassing the passive, evocative, and active versions of the same; see DiLalla \& Gottesman, 1991; Plomin, DeFries, \& Loehlin, 1977), in that both the latent trait and the outcomes of each immediately prior developmental stage are hypothesized to influence the outcomes at each successive stage in systematically dissimilar ways for different individuals, depending on both one's level of the trait and on the specific social interactions encountered at each successive in of environment. One cannot as easily paraphrase this model in any simplistic popular expression of which we are aware.

We evaluated the relative performance of these three alternative models in accounting for the covariance structure of three independents samples: a larger and nationally-representative sample of the adult USA population, a convenience sample of USA college students (from a large Southwestern university), and a combined and equality-constrained convenience sample of Latin American college students (from one large Mexican and one large Costa Rican university, located in the capital of each respective country).

The results of the hierarchical nested model comparisons were qualitatively identical for all three studies: the Integrative Biopsychosocial Model significantly outperformed both the developmental pathways model and the common factor trait model in all practical and statistical indices of adequacy of fit to the data. We interpret this as supporting the conclusion that the Integrative Biopsychosocial Model, in which both heritable life history speed and expanding spheres of interaction with the social environment explain the data substantially better than either one of these sources of influence alone.

\section{Limitations of the Study}

One major limitation of these studies is that they were all based on cross-sectional rather than longitudinal data. In spite of our efforts to array the domain-specific resource allocation subscales in a theoretically specified developmental sequence, ultimately all of the data presented 
were based on retrospective self-report at a single point in time in either young or late adulthood.

Furthermore, we admittedly tested extreme versions of both the trait model and the developmental model. Nevertheless, we believe that the unequivocal rejection of these overly simplistic models in relation to the Integrative Biopsychosocial Model is instructive. Although no researcher that we are aware of has explicitly endorsed these extreme models, some often appear to emphasize the veracity of one over that of the other, if only by omission and implication. The finding that both extreme models are incomplete should therefore serve as a caution, advising both ourselves and others to better qualify their statements and avoid appearing to endorse the primacy of one category of influences to the exclusion of the other.

Despite these acknowledged limitations, the generality of these findings across these three sociodemographically diverse samples gives us increased confidence in the robustness of our findings, at least as bounded by the limits of the specific methodologies applied. We hope that these findings will serve to resolve some of the ongoing controversies regarding the relative validities of these two alternative models of life history development and point the way towards a more comprehensive and conciliatory approach to the problem.

Author notes: Corresponding author: Rafael Antonio Garcia, email: ragarci2@email.arizona.edu. The Authors would like to thank the anonymous reviewers of this paper for their valuable input.

\section{References}

Belsky, J., Steinberg, L., \& Draper, P. (1991). Childhood experience, interpersonal development, and reproductive strategy: An evolutionary theory of socialization. Child Development, 62, 647-670.

Bentler, P. M. (1990). Fit indices, Lagrange Multipliers, constraint changes, and incomplete data in structural models. Multivariate Behavioral Research, 25, 163-172.

Bentler, P. M. (1995). EQS: Structural equations program manual. Los Angeles, CA: Multivariate Software.

Bentler, P. M., \& Bonnett, D. G. (1980). Significance tests and goodness of fit in the analysis of covariance structures. Psychological Bulletin, 88, 588-606.

Brim, O. G., Baltes, P. B., Bumpass, L. L., Cleary, P. D., Featherman, D. L., Hazzard, W. R., Kessler, R. C. M., Lachman, E., Markus, H. R., Marmot, M. G., Rossi, A. S., Ryff, C. D., \& Shweder, R. A. (2000). National survey of midlife development in the United States MIDUS), 1995-1996 [Computer file]. ICPSR version. Ann Arbor, MI: DataStat, Inc./Boston, MA: Harvard 
Medical School, Dept. of Health Care Policy [producers], 1996. Ann Arbor, MI: Inter-university Consortium for Political and Social Research [distributor], 2000.

Bronfenbrenner U., \& Ceci S. (1994). Nature-nurture reconceptualized in developmental perspective: A bioecological model. Psychological Review, $101,568-586$.

Bronfenbrenner, U., \& Morris, P. A. (2006). The bioecological model of human development. In W. Damon \& R. M. Lerner (Eds.), Handbook of child psychology, Volume 1, Theoretical Models of Human Development, 6th Edition (793-828). Hoboken, New Jersey: John Wiley \& Sons, Inc.

Browne, M. W., \& Cudeck, R. (1993). Alternative ways of assessing model fit. Sociological Methods and Research, 21, 230-258.

Byrne, B. M. (1994). Structural Equation Modeling With EQS and EQS/Windows. Newbury Park: Sage.

Cabeza de Baca, T., Barnett, M. A., Ellis, B. J. (2016). The development of the child unpredictability schema: The correlates of maternal life history tradeoffs on reproductive effort. Evolutionary Behavioral Sciences, 10, 4355. http://dx.doi.org/10.1037/ebsooooo56

Cabeza de Baca, T. and Figueredo, A. J. (2014). The cognitive ecology of Mexico: climatic and socio-cultural effects on life history strategies and cognitive abilities. Intelligence, 47, 63-71.

Copping, L. T., Campbell, A., \& Muncer, S. (2014). Psychometrics and life history strategy: The structure and validity of the high K strategy scale. Evolutionary Psychology, 12, 200-222.

Cronbach, L. J. \& Meehl, P. E. (1955). Construct validity in psychological tests. Psychological Bulletin, 52, 281.

Del Giudice, M. (2014). A tower unto heaven: Response to commentaries on "An evolutionary life history framework for psychopathology". Psychological Inquiry, 25, 261-300

DiLalla, L. F., \& Gottesman, I. I. (1991). Biological and genetic contributions to violence: Widom's untold tale. Psychological Bulletin, 109, 125-129.

Ellis, B. J. (2004). Timing of pubertal maturation in girls: An integrated life history approach. Psychological Bulletin, 130, 920-958.

Ellis, B. J., Figueredo, A. J., Brumbach, B. H., \& Schlomer, G. L. (2009). Fundamental dimensions of environmental risk: The impact of harsh versus unpredictable environments on the evolution and development of life history strategies. Human Nature, 2O, 204-268.

Figueredo, A .J., Wolf, P. S. A., Olderbak, S. G., Gladden, P. R., Fernandes, H. B. F., Wenner, C., Hill, D., Andrzejczak, D. J., Sisco, M. M., Jacobs, W .J., Hohman, Z. J., Sefcek, J. A., Kruger, D., Howrigan, D. P., MacDonald, K., \& Rushton, J. P. (2014). The psychometric assessment of human life history strategy: A meta-analytic construct validation. Evolutionary Behavioral Sciences, 8, 148-185.

Figueredo, A. J. (2007). The Arizona Life History Battery [Electronic Version]. http://www.u.arizona.edu/ ajf/alhb.html

Figueredo, A. J., \& Rushton, J.P. (2009). Evidence for shared genetic dominance between the general factor of personality, mental and physical health, and life history traits. Twin Research and Human Genetics, 12, 555-563. 
Figueredo, A. J., Cabeza de Baca, T., \& Black, C. J. (2014). No matter where you go, there you are: The genetic foundations of temporal stability. Journal of Methods and Measurement in the Social Sciences, 5, 76-106.

Figueredo, A. J., Cabeza de Baca, T., \& Black, C. J. (2014). No matter where you go, there you are: The genetic foundations of temporal stability. Journal of Methods and Measurement in the Social Sciences, 5, 76-106.

Figueredo, A. J., Cabeza de Baca, T., Black, C. J., Garcia, R. A., Fernandez, H. B. F., Wolf, P. S. A., \& Woodley of Menie, M. A. (2015). Methodologically Sound: Evaluating the Psychometric Approach to the Assessment of Human Life History [Reply to Copping, Campbell, \& Muncer, 2014]. Evolutionary Psychology, 13, 299-338.

Figueredo, A. J., Hammond, K.R., \& McKiernan, E. C. (2006). A Brunswikian evolutionary developmental theory of preparedness and plasticity. Intelligence, 34, 211-227.

Figueredo, A. J., McKnight, P.E., McKnight, K. M., \& Sidani, S. (2000). Multivariate modeling of missing data within and across assessment waves. Addiction, 95 (Supplement 3), S361-S380.

Figueredo, A. J., Patch, E. A., \& Gómez Ceballos, E. (2015). A life history approach to the dynamics of social selection. In V. Zeigler-Hill, L. Welling, \& T. K. Shackelford (Eds.), Evolutionary Perspectives on Social Psychology (pp. 364-372). Switzerland: Springer International Publishing.

Figueredo, A. J., Vásquez, G., Brumbach, B. H., \& Schneider, S. M. R. (2007). The K-factor, covitality, and personality: A psychometric test of life history theory. Human Nature, 18, 47-73.

Figueredo, A. J., Vásquez, G., Brumbach, B. H., Schneider, S. M. R., Sefcek, J. A., Tal, I. R., Hill, D., Wenner, C. J., \& Jacobs, W. J. (2006). Consilience and life history theory: From genes to brain to reproductive strategy. Developmental Review, 26, 243-275.

Figueredo, A. J., Vásquez, G., Brumbach, B. H., Sefcek, J. A., Kirsner, B. R., \& Jacobs, W. J. (2005). The K-Factor: Individual differences in life history strategy. Personality and Individual Differences, 39, 1349-1360.

Figueredo, A. J., Vásquez, G., Brumbach, B. H., \& Schneider, S. M. R. (2004). The heritability of life history strategy: The K-factor, covitality, and personality. Social Biology, 51, 121-143.

Figueredo, A. J., Vásquez, G., Brumbach, B.H., \& Schneider, S.M.R. (2007). The K-factor, covitality, and personality: A psychometric test of life history theory. Human Nature, 18, 47-73.

Figueredo, A. J., Woodley, M. A., Brown, S. D., \& Ross, K. C. (2013). Multiple successful test of the strategic differentiation-integration effort (SD-IE) hypothesis. Journal of Social, Evolutionary, and Cultural Psychology, 7, 361383.

Gorsuch, R. L. (1983). Factor Analysis (2 ${ }^{\text {nd }}$ Edition). Hillsdale, NJ: Erlbaum.

Hu, L. T., \& Bentler, P. M. (1995). Evaluating model fit. In R. H. Hoyle (Ed.), Structural equation modeling: Concepts, issues, and applications (pp. 7699). Thousand Oaks, CA: Sage

Lakatos, I. (1978). The Methodology of Scientific Research Programmes: Philosophical Papers Volume 1. Cambridge: Cambridge University Press. 
Lemery-Chalfant, K., Kao, K., Swann, G., \& Goldsmith, H. H. (2013). Childhood temperament: Passive gene-environment correlation, gene-environment interaction, and the hidden importance of the family environment. Development and psychopathology, 25, 51-63.

Marsh, H. W., \& Bailey, M. (1991). Confirmatory factor analyses of multitraitmultimethod data: A comparison of alternative models. Applied Psychological Measurement, 15, 47-70.

McArthur, R. H., \& Wilson, E. O. (1967). The theory of island biogeography. Princeton, NJ: Princeton University Press.

McKnight, P. E., McKnight, K. M., Sidani, S. \& Figueredo, A. J. (2007). Missing Data: A Gentle Introduction. New York, NY: Guilford.

Nettle, D., Coal, D. \& Dickins, T. (2011) Early life conditions and age of first pregnancy in British women. Proceedings of the Royal Society B., 1721-1727.

Pianka, E. R. (1970). On r- and K-selection. American Naturalist, 104, 592-597.

Plomin, R., DeFries, J. C., \& Loehlin, J. C. (1977). Genotype-environment interaction and correlation in the analysis of human behavior. Psychological Bulletin, 84, 309-322.

Ross L. T. and Hill E. M. (2002). Childhood unpredictability, schemas for unpredictability, and risk taking. Social Behavior and Personality, 3o, 453.

Rushton, J. P. (2004). Placing intelligence into an evolutionary framework or how $g$ fits into the $r-K$ matrix of life-history traits including longevity. Intelligence, 32, 321-328.

Sotomayor-Peterson, M., Cabeza de Baca, T., Figueredo, A. J., \& Smith-Castro, V. (2013). Shared parenting, total parental effort, and life history strategy: A cross-cultural comparison. Journal of Cross-Cultural Psychology, 44, 620639.

Steiger, J. H., \& Lind, J. C. (1980). Statistically-based tests for the number of common factors. Paper presented at the annual Spring Meeting of the Psychometric Society in Iowa City. May 30, 1980.

Wachs, T. D. (2009).Viewing microsystem chaos through a Bronfenbrenner Bioecological lens. In Evans, G. W. \& Wachs, T. D (Eds.) Chaos and its influence on children's development: An ecological perspective (pp. 97-112). Washington DC: American Psychological Association.

Waddington, C. H. (1957). The strategy of genes. London: Allen \& Unwin.

West-Eberhard, M. J. (2003). Developmental plasticity and evolution. New York: Oxford University Press.

Widaman, K. F. (1985). Hierarchically nested covariance structure models for multitrait-multimethod data. Applied Psychological Measurement, 9, 1-26.

Wilson, E. O. (1975). Sociobiology: The new synthesis. Cambridge, MA: Harvard University. 


\section{Appendix}

\section{Study 1: Figures}

Figure A. Study 1 Trait Only Model Results

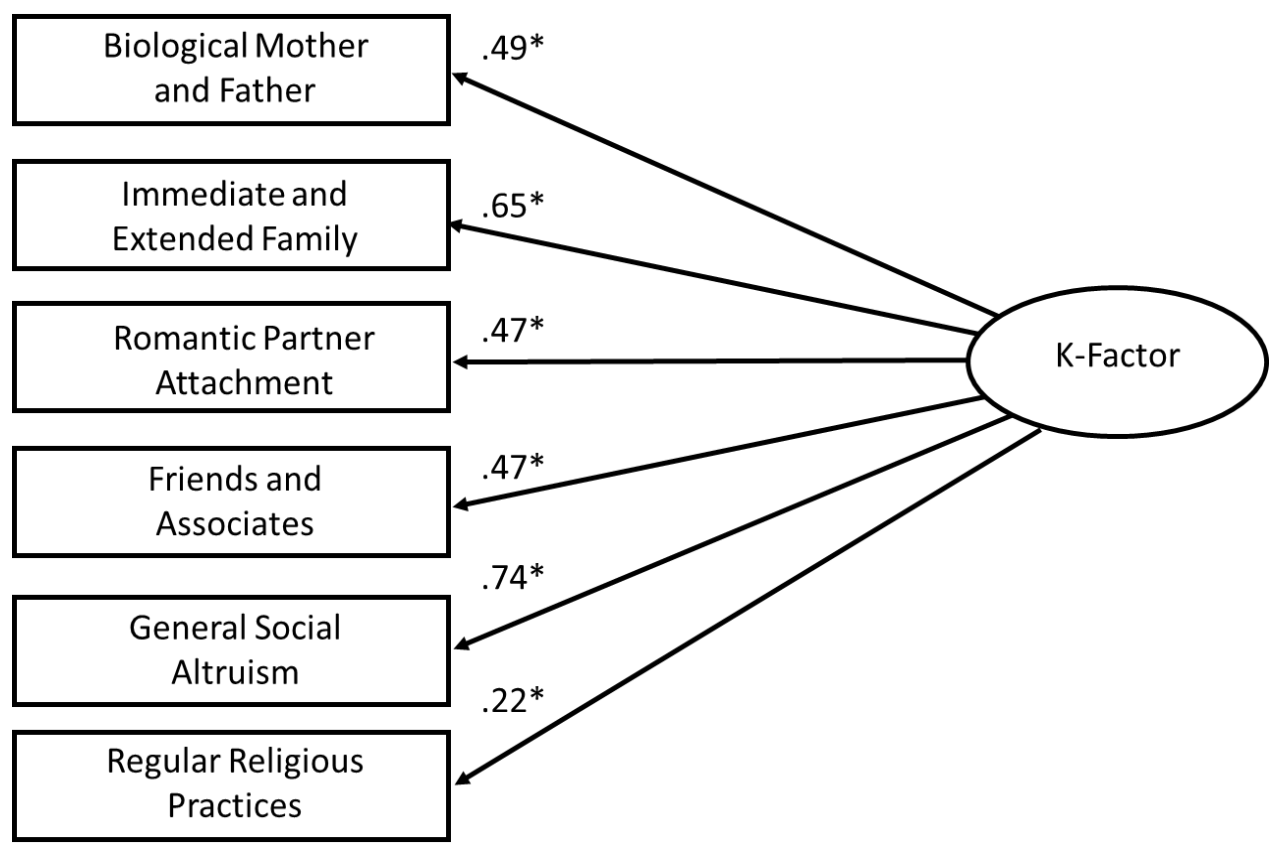

Figure B. Study 1 Developmental Pathways Only Model Results

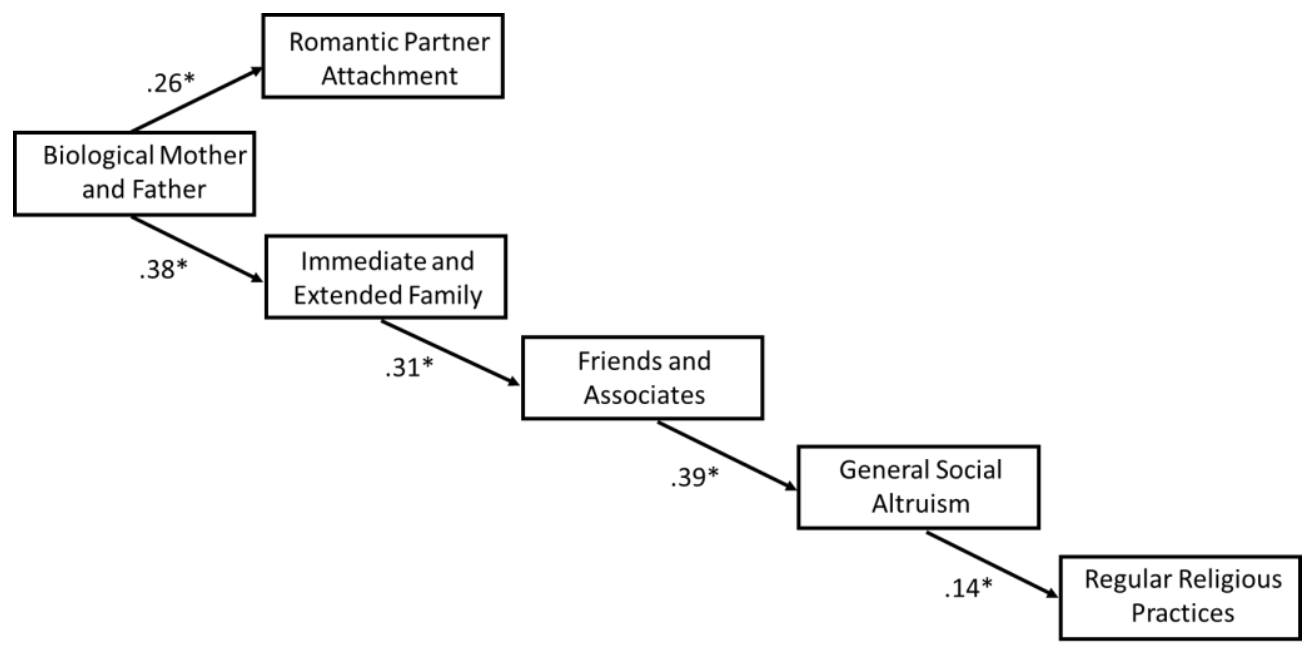


Figure C. Study 1 Trait plus Developmental Pathways Model Results

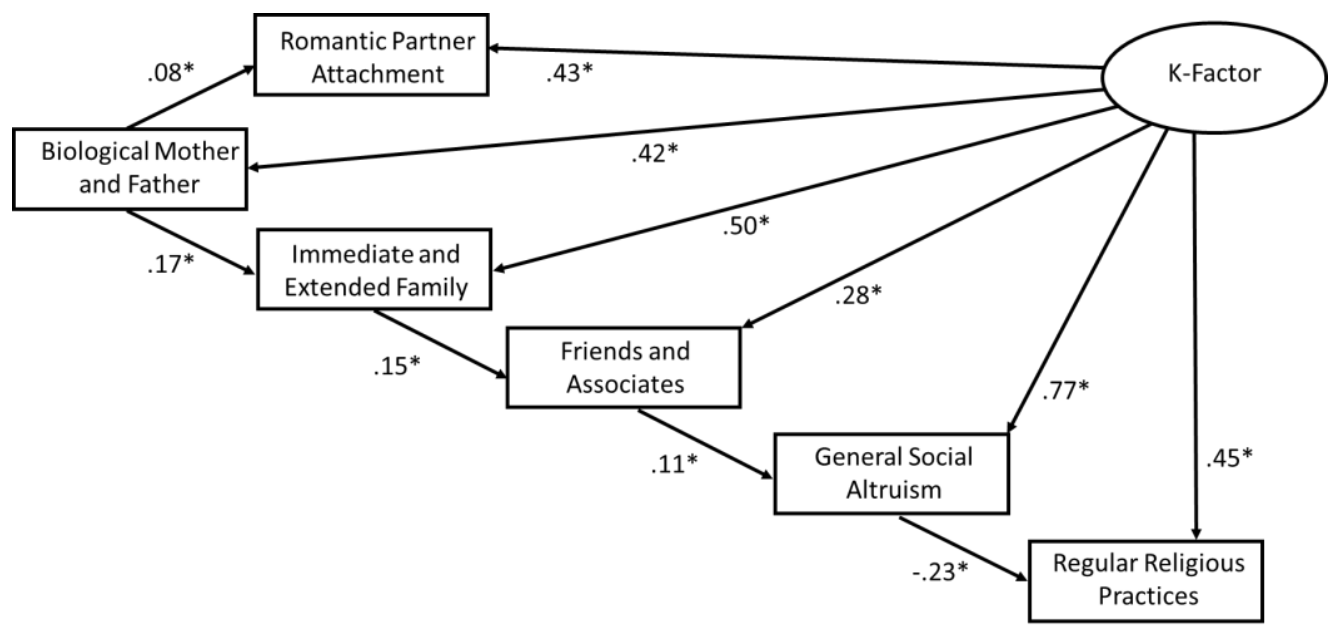

\section{Study 2: Figures}

Figure D. Study 2 Trait Only Model Results

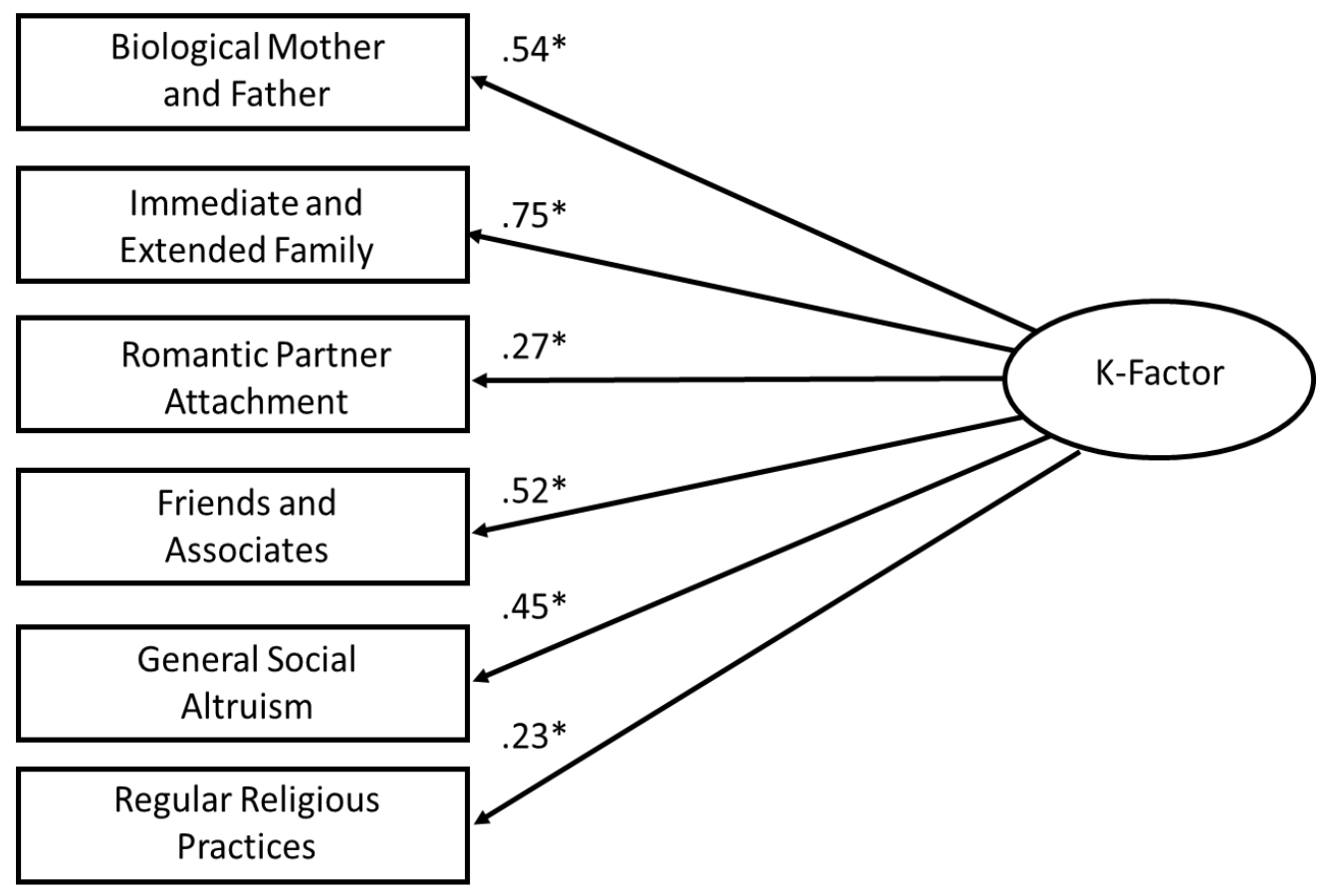


Figure E. Study 2 Developmental Pathways Only Model Results

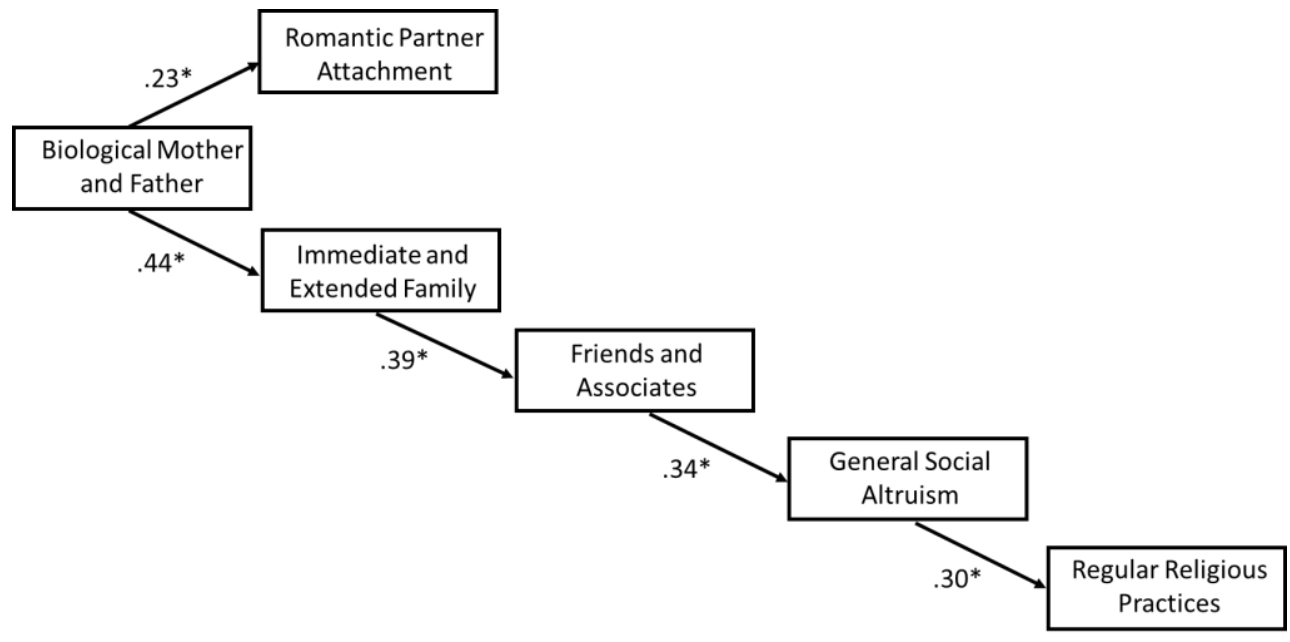

Figure F. Study 2 Trait Only Model with Mini-K as Proxy for Latent Common K-Factor

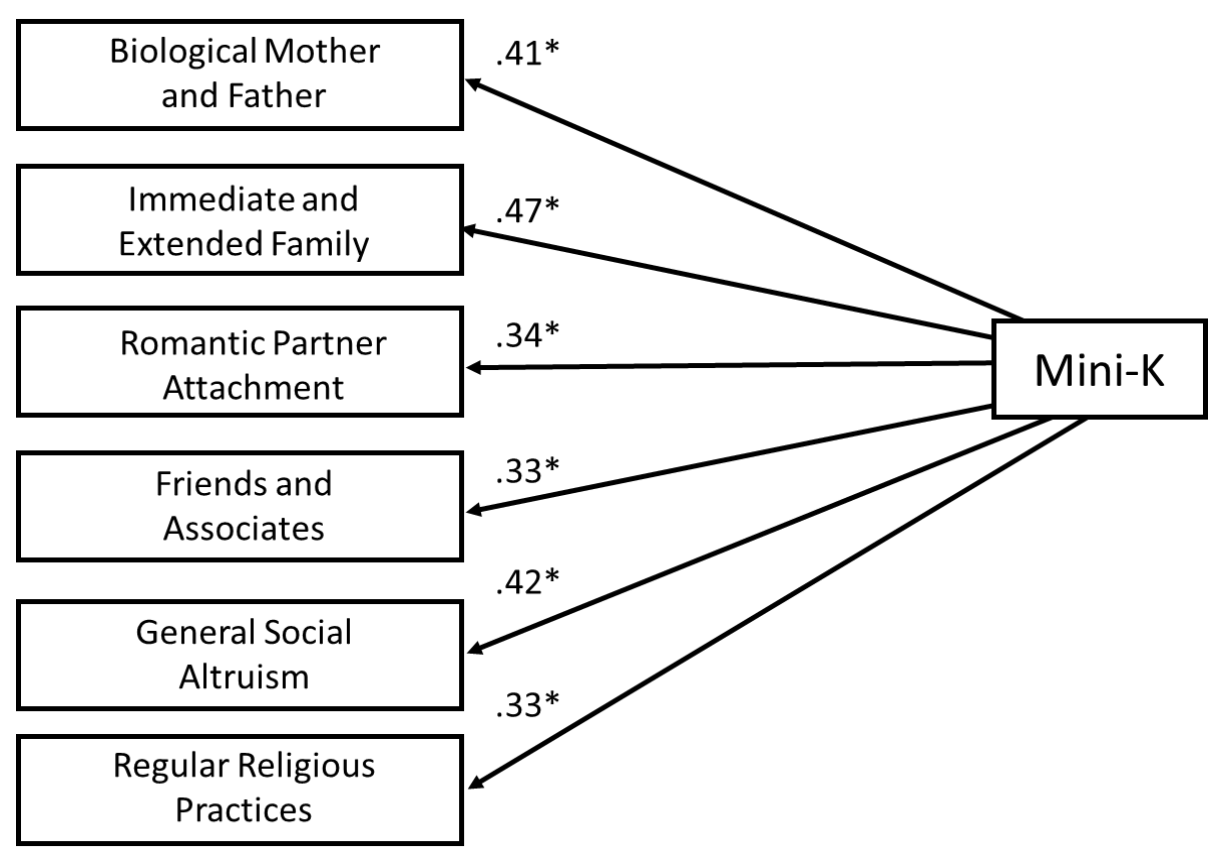




\section{GARCIA ET AL.}

Figure G. Study 2 Developmental Pathways Model with Mini-K as Emergent Variable

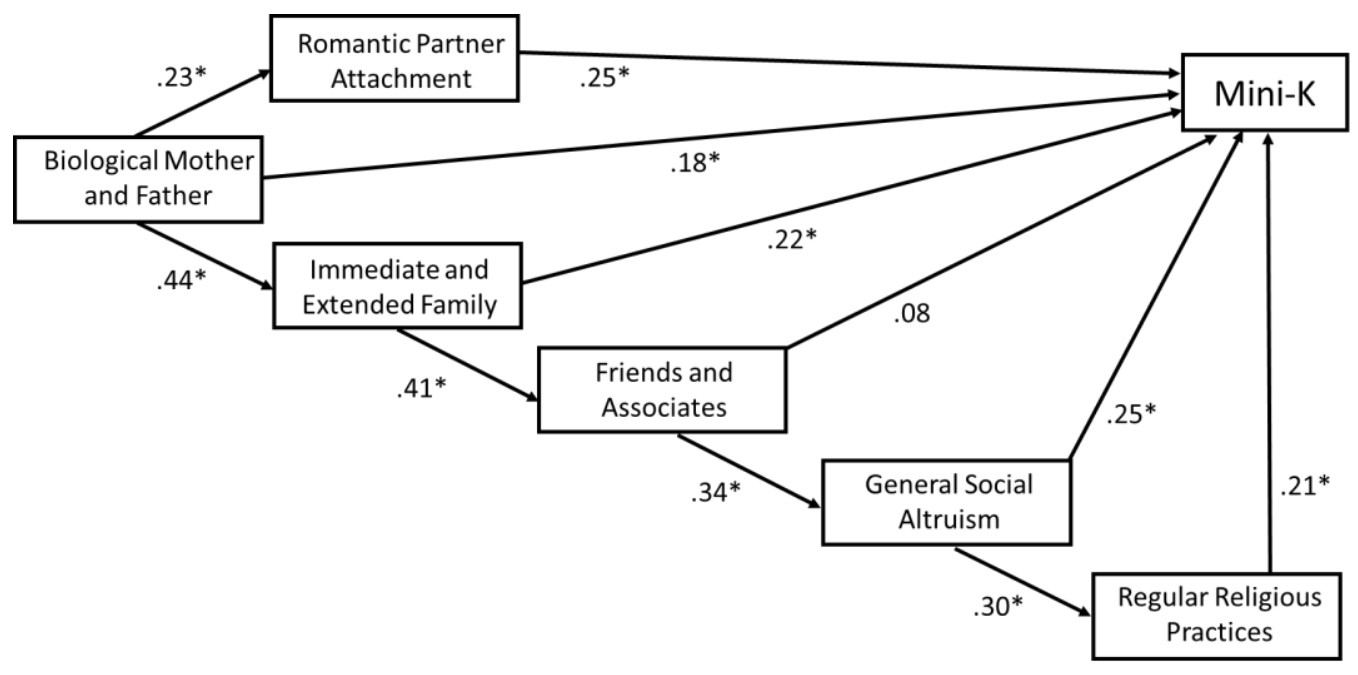

Figure H. Study 2 Integrative Trait plus Developmental Pathways Epigenetic Model Results with Mini-K as Proxy for Latent Common KFactor

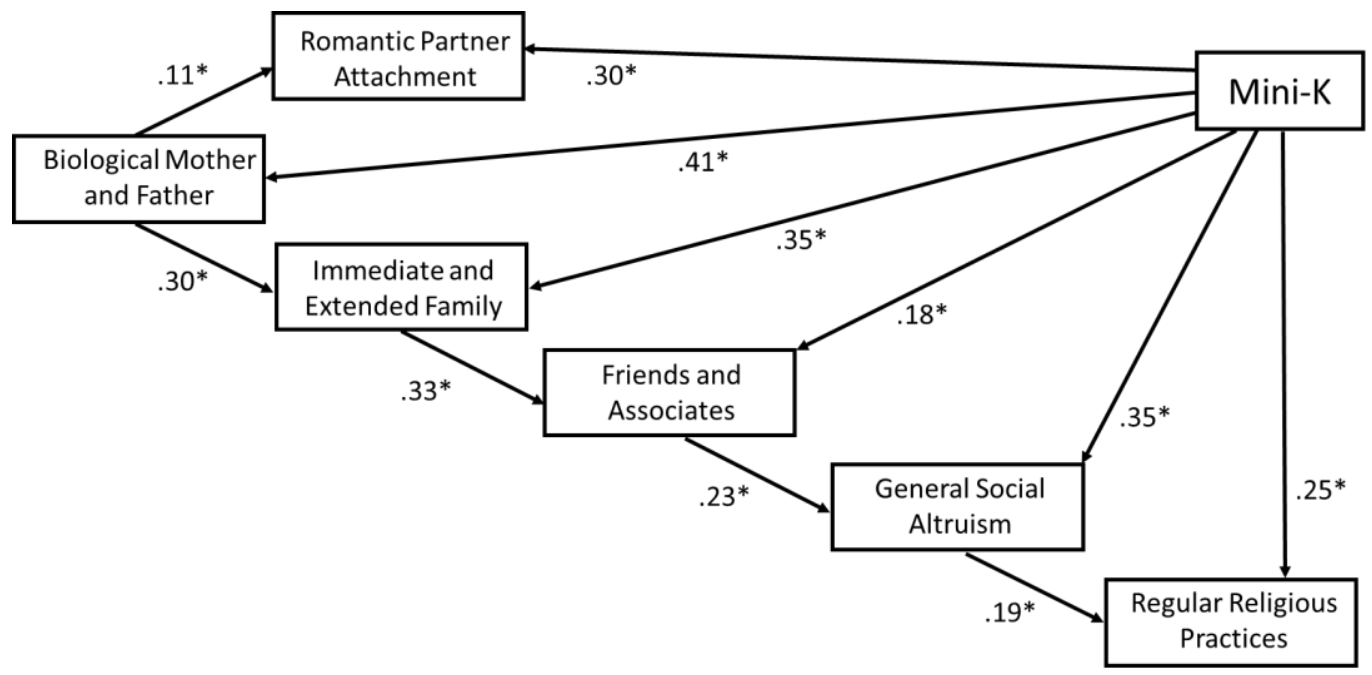




\section{Study 3: Figures}

Figure I. Study 3 Trait Only Model Results

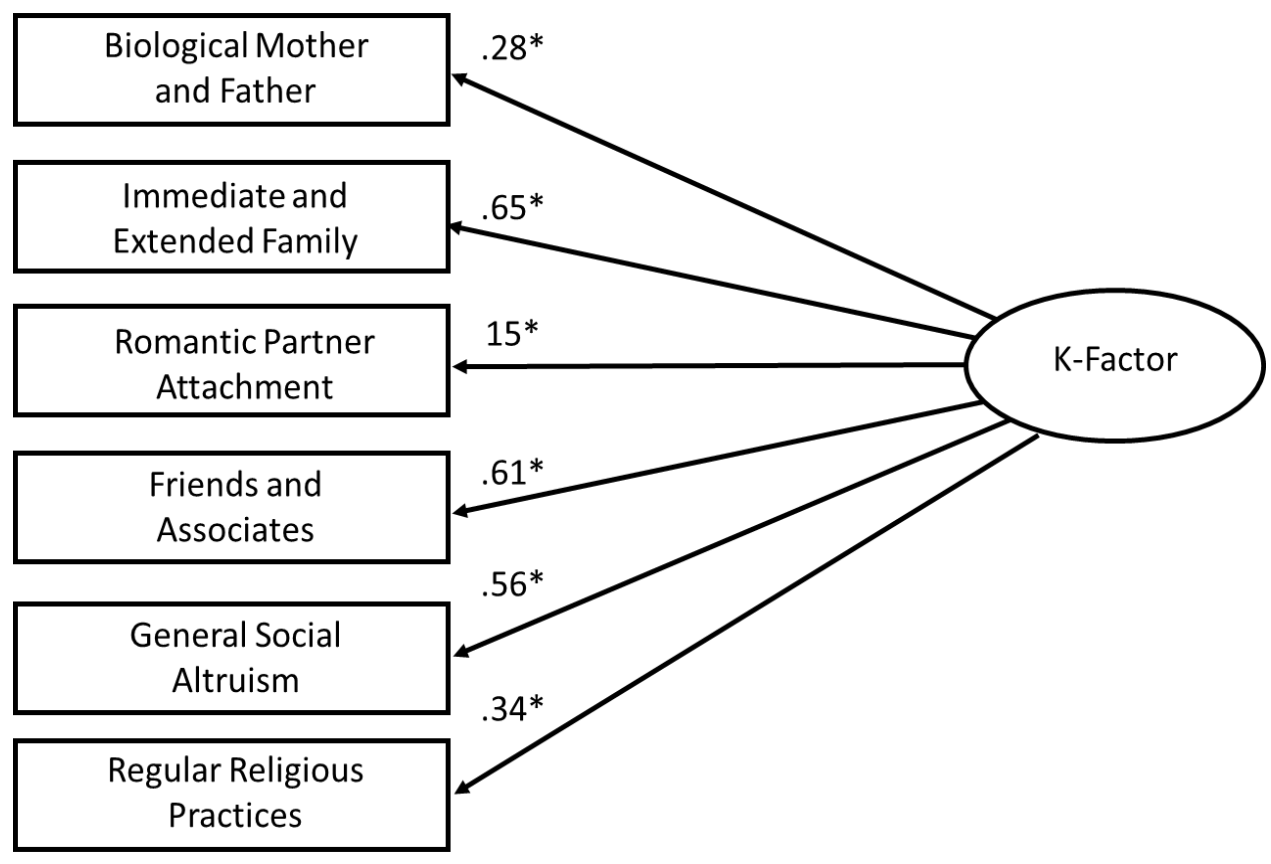

Figure J. Study 3 Developmental Pathways Only Model Results

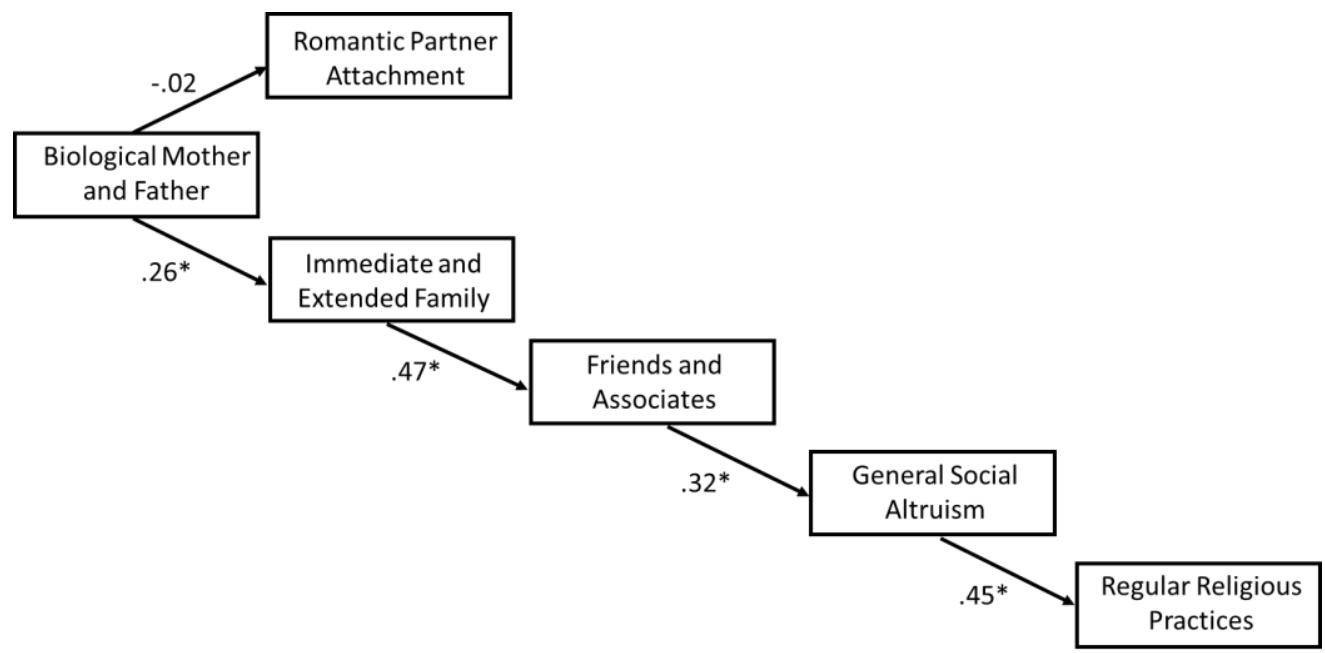


Figure K. Study 3 Trait Only Model with Mini-Kas Proxy for Latent Common K-Factor

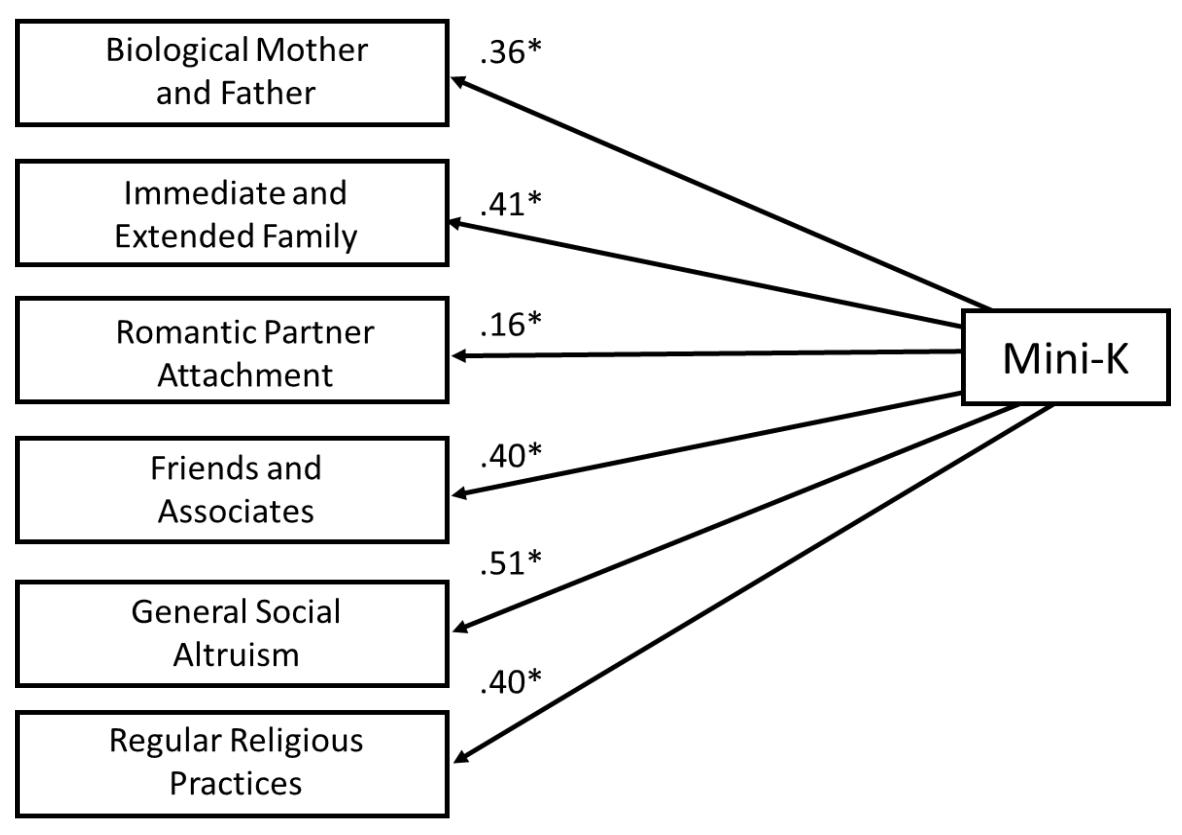

Figure L. Study 3 Developmental Pathways Model with Mini-K as Emergent Variable

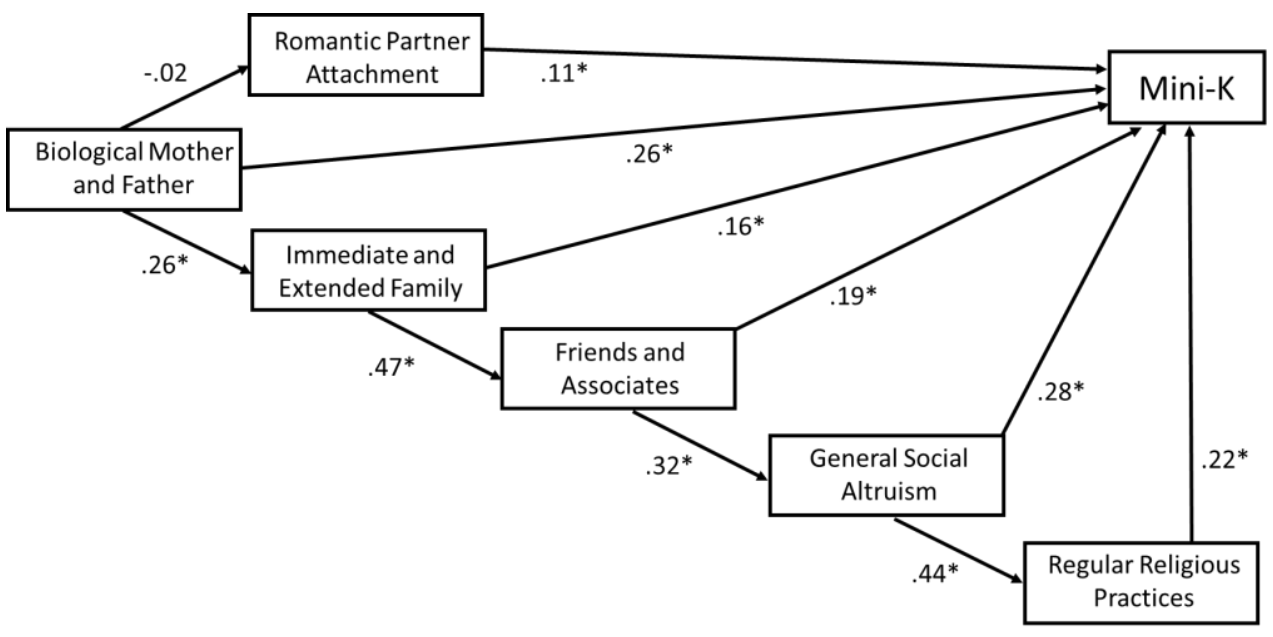




\section{RESOURCE ALLOCATION IN LIFE HISTORY STRATEGY}

Figure M. Study 3 Integrative Trait plus Developmental Pathways Epigenetic Model Results with Mini-K as Proxy for Latent Common KFactor

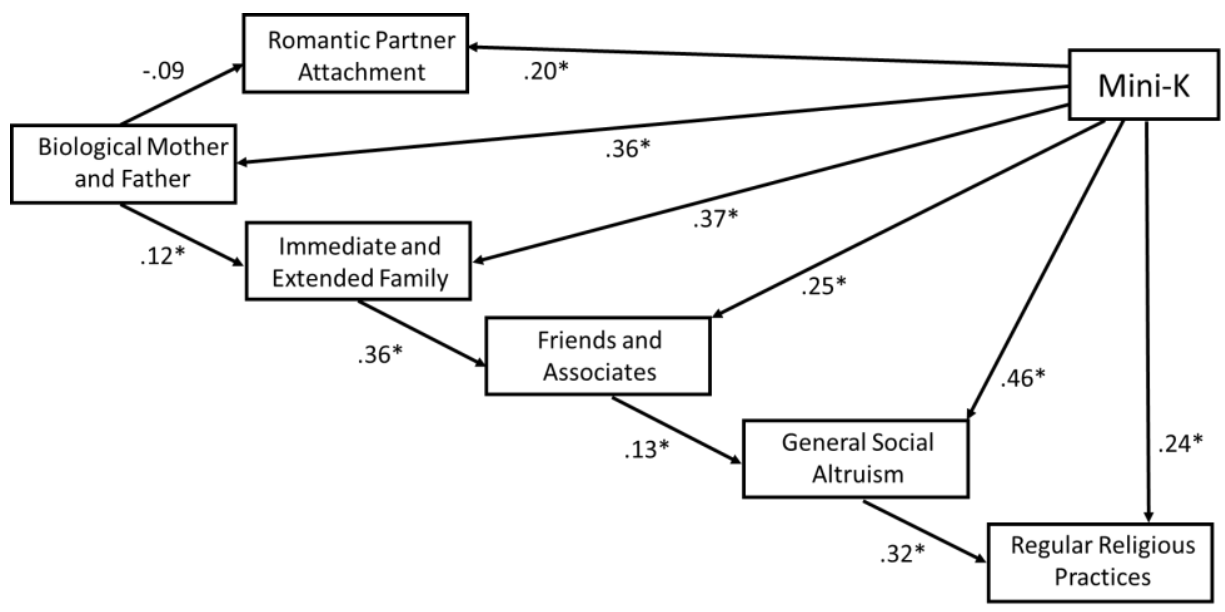

